\title{
Effects of moisture absorption on damage progression and strength of unidirectional and cross-ply fiberglass-epoxy composites
}

\author{
Jake D. Nunemaker, Michael M. Voth, David A. Miller, Daniel D. Samborsky, Paul Murdy, and \\ Douglas S. Cairns
}

Mechanical and Industrial Engineering Department, Montana State University, Bozeman, MT 59717, USA

Correspondence: David A. Miller (davidmiller@montana.edu)

Received: 6 February 2018 - Discussion started: 14 February 2018

Revised: 4 May 2018 - Accepted: 15 May 2018 - Published: 20 June 2018

\begin{abstract}
Fiber-reinforced-polymer composites (FRPs) possess superior mechanical properties and formability, making them a desirable material for construction of large optimized mechanical structures, such as aircraft, wind turbines, and marine hydrokinetic (MHK) devices. However, exposure to harsh marine environments can result in moisture absorption into the microstructure of the FRPs comprising these structures and often degrading mechanical properties. Specifically, laminate static and fatigue strengths are often significantly reduced, which must be considered in design of FRP structures in marine environments. A study of fiberglass epoxy unidirectional and cross-ply laminates was conducted to investigate hygrothermal effects on the mechanical behavior of a common material system used in wind applications. Several laminates were aged in $50^{\circ} \mathrm{C}$ distilled water until maximum saturation was reached. Unconditioned control and the saturated samples were tested in quasi-static tension with the accompaniment of acoustic emission (AE) monitoring. Cross-ply laminates experienced a $54 \%$ reduction in strength due to moisture absorption, while unidirectional laminate strengths were reduced by $40 \%$. Stress-strain curves and AE activity of the samples were analyzed to identify changes in damage progression due to aging.
\end{abstract}

\section{Introduction}

\subsection{Composites and renewable energy technologies}

Fiber-reinforced polymers (FRPs) offer desirable properties for development of large mechanical structures, such as wind turbines and more recently marine hydrokinetic (MHK) devices. High specific strength and stiffness, the ability to tailor the anisotropic properties, and low costs make FRPs the primary choice for optimizing the design of energy-harvesting devices (Samborsky et al., 2012). Additionally, the formability of FRPs enables the manufacture of complex geometry and structures necessary in the wind and MHK industry. As wind energy becomes a more dominant energy source, and as MHK technology progresses, it is paramount to understand how FRPs perform throughout a device's designed lifetime. Inherently, this means characterizing material degradation from environmental exposure. This research explores how exposure to a wet environment affects the mechanical response of fiberglass epoxy laminates. Effort is made to characterize the effect of moisture on composites on a coupon level, which can provide insight to subsequent component and structure design.

\subsection{Hygrothermal aging of fiber-reinforced plastics}

FRPs typically exhibit Fickian diffusion, primarily through the matrix material as fiberglass typically absorbs a negligible amount of moisture. Other modes are possible, but defect driven; poorly bonded fiber-matrix interfaces and porosity provide these secondary diffusion pathways (Sun et al., 2011; Tsenoglou et al., 2006). At ambient design temperatures moisture diffusion occurs over time periods impractical for study in the laboratory setting. The rate-temperature 
relationship of the Arrhenius law applies for moisture diffusion in FRPs (Tsai et al., 2009), and allows test specimens to be aged at elevated temperatures to increase diffusion rates. Elevated aging temperatures are chosen to increase diffusion rates without degrading the temperature-sensitive matrix material. Exceedingly high temperatures can alter the material physically or chemically as evidenced by non-Fickian diffusion and/or changes in glass transition temperature (Tsai et al., 2009; Grammatikos et al., 2016).

Past research has shown significant reductions in both static and fatigue performance due to moisture absorption (Mourad et al., 2010; Miller et al., 2012; Liao et al., 1999; Komai et al., 1991; Siriruk and Penumadu, 2014; Nunemaker, 2017, 2016). MHK devices and wind turbines fall into the fatigue loading regime, but material characterization through static tests is essential to understanding the changes in performance anticipated under cyclic loading and the mechanism responsible. Changes in material performance due to conditioning are a consequence of changes in the mechanical behavior of the matrix and quality of the fiber-matrix interface. Water is a known plasticizer in polymers; water molecules disrupt interactions between polymer chains, resulting in increased chain mobility and ultimately leading to degraded mechanical properties. Moisture-induced plasticization has been observed experimentally through changes in viscoelastic properties and glass-transition temperature of neat resin (Zhou and Lucas, 1999a, b; Nogueira et al., 2001). Interface integrity is more challenging to determine experimentally, but scanning electron microscope (SEM) images of fracture surfaces of aged composites have provided evidence of a weakened interface bond (Mourad et al., 2010; Liao et al., 1999).

Understanding matrix and interface response to hygrothermal aging is essential to better understanding of how moisture absorption affects FRPs at a micromechanical level. However, the changes in matrix and the interface properties can be difficult to translate to the mechanical response of the laminate and do not fully describe the macroscopic damage progression of the material. Thus, laminate-scale testing is still necessary to characterize mechanical behavior of these materials in hygrothermal environments. Unidirectional tension and transverse tension are commonly used to characterize the change in mechanical response due to hygrothermal aging (Miller et al., 2012). These tests can be applied to predict behavior of more complex laminates; however, this approach does not incorporate hygrothermal effects on ply interactions. This research expands this idea to experimentally examine cross-ply laminates and unidirectional laminas in both unconditioned and fully conditioned states and to investigate the effects of hygrothermal aging on the mechanical response and damage progression of multi-angle laminates.

\subsection{Composites and acoustic emission}

Damage progression at the micromechanical level is difficult to experimentally observe. In situ acoustic emission (AE) monitoring is a technique that enables real-time observation of damage events using piezoelectric sensors mounted on the surface of the test specimen to record damage-initiated elastic waves propagating through the material. These waveforms can provide useful information for both structural health monitoring and material characterization purposes. For this research, material characterization is the focus, with the intent of using acoustic events to help characterize changes in damage progression due to environmental aging.

$\mathrm{AE}$ is an indirect method of measurement and therefore requires thorough analysis to correlate $\mathrm{AE}$ activity to micromechanical damage within the material. Many analysis techniques exist, including single-parameter analysis (Bourchak et al., 2007; Suzuki et al., 1987; deGroot et al., 1995; Ramirez-Jimenez et al., 2004), clustering and artificial neural networks (ANNs) (Gutkin et al., 2011; Suresh Kumar et al., 2017; Pashmforoush et al., 2012), and detailed waveform analysis (Ni and Iwamoto, 2002; Surgeon and Wevers, 1999; Voth, 2017). In this study, single-parameter methods of fastFourier-transform (FFT) peak frequency and event energy are used to characterize the damage progression of the material. Past research has attempted to correlate FFT peak frequencies in $\mathrm{AE}$ waveforms to specific damage mechanisms, while energy has been shown to correlate with damage accumulation in the material (Bourchak et al., 2007; Kumar et al., 2017). When used as parameters for ANN, energy, and other parameters indicative of damage event magnitude, such as counts and number of hits, have successfully been used to predict residual strength (Suresh Kumar et al., 2017). Although multivariable techniques permit relationships to be made among many AE parameters in the analysis, differentiating among damage mechanisms remains a challenge. Clustering studies have shown that frequency content of $\mathrm{AE}$ waveforms persists as a dominant parameter for differentiating types of damage events (Gutkin et al., 2011; Pashmforoush et al., 2012).

Previous research incorporating $\mathrm{AE}$ monitoring in the evaluation of hygrothermally aged composites has revealed that moisture uptake frequently causes a decrease in AE response in terms of energy, amplitude, number of events, and counts (Assarar et al., 2011; Czigány et al., 1995; Garg and Ishai, 1985a, b; Hamstad, 1983; Komai et al., 1991). However, this may not always be the case: a recent delamination study showed an increase in magnitude of AE response in terms of energy and amplitude for conditioned delamination samples (Liu et al., 2017). Changes in the magnitude of the $\mathrm{AE}$ response due to moisture have not been thoroughly explored or understood, but have been theorized to be an effect of matrix plasticization and its effect on signal attenuation and damage source behavior. Consideration of this change in $\mathrm{AE}$ response is important when analyzing $\mathrm{AE}$ results, and can 
help differentiate changes in AE response associated with damage behavior from effects of moisture on the AE propagation behavior.

\section{Experimentation}

\subsection{Materials}

Vectorply E-LT 3800, a stitched E-glass fabric consisting of $1138 \mathrm{~g} \mathrm{~m}^{-2}(91 \%)$ of unidirectional tows and $114 \mathrm{~g} \mathrm{~m}^{-2}$ ( $9 \%$ ) of transverse backing fibers, was utilized in this study. The architecture represents reinforcements commonly used in wind turbine blades. Although commonly treated as a unidirectional fabric, the $9 \%$ backing fibers can have notable effects on laminate behavior, as discussed later. Four laminates, $[0]_{2},[90]_{2},[0 / 90]_{s}$, and $[90 / 0]_{s}$, were tested in this study. The $[0]_{2}$ and $[90]_{2}$ laminates were chosen to be representative of individual 0 and $90^{\circ}$ lamina. Both $[0 / 90]_{s}$ and $[90 / 0]_{s}$ were tested to compare variation due to the stacking sequence. EPIKOTE RIMR 135 epoxy resin with EPIKURE RIMH 1366 hardener, manufactured by Hexion, was used as the resin system. Laminates were manufactured using vacuumassisted resin infusion, and cured at $22{ }^{\circ} \mathrm{C}$ for $24 \mathrm{~h}$ followed by a $12 \mathrm{~h}$ post cure at $70^{\circ} \mathrm{C}$ as per the resin specifications. Resulting fiber volume fractions varied between 55 and $58 \%$. Test specimens were cut to $30 \mathrm{~mm} \times 300 \mathrm{~mm}$ with a diamond abrasion saw. G10 fiberglass tabs measuring $64 \mathrm{~mm} \times 30 \mathrm{~mm}$ were adhered to all test specimens with an epoxy adhesive, as seen in Fig. 2, to reduce effects of the gripping pressure throughout tensile testing.

\subsection{Hygrothermal aging}

Samples were hygrothermally aged by immersion in distilled water maintained at $50^{\circ} \mathrm{C}$. Other work by the authors has confirmed that temperature conditioning alone at $50^{\circ} \mathrm{C}$ does not degrade the epoxy glass system used in this study (Voth, 2018). A scale with a $0.001 \mathrm{~g}$ resolution was used to measure the initial mass of the samples and subsequent mass changes due to moisture uptake. The bulk moisture uptake, $M(t)$, is given by Eq. (1), where $m_{t}$ is the mass of the sample during moisture sorption and $m_{i}$ is the mass prior to absorption. Sample masses were measured on witness coupons without tabs, thus bulk moisture contents reflect those of just the composite of interest.

$M(t)=\frac{m_{t}-m_{i}}{m_{i}}$

Test specimens reached saturation when the bulk moisture content reached equilibrium, seen by the plateau to asymptotic Fickian behavior in the bulk diffusion curves shown in Fig. 1. The plateau was identified by negligible changes in the bulk uptake after subsequent measuring steps (100$150 \mathrm{~h}$ ). The saturated moisture content, $m_{\infty}$, ranged between

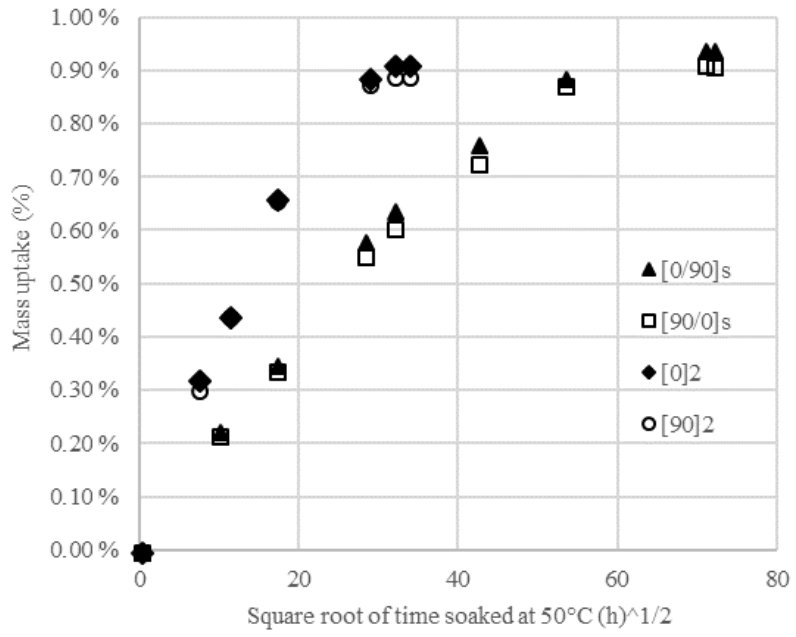

Figure 1. Moisture uptake curves.

0.89 and $0.94 \%$, and was consistent among all layups. Similar uptakes among layups which feature consistent volume fractions support that equilibrium was reached. Fully conditioned samples are referred to as "saturated". Control samples in the as-manufactured state, with no conditioning of any type, are referred to as "dry"; however, as no drying was conducted post-manufacturing, small amounts of moisture could be present from the manufacturing process.

\subsection{Testing}

\subsubsection{Tensile testing}

Five tensile tests were conducted for each laminate in both the dry and saturated conditions, in accordance with ASTM D3039 (2014). Testing took place using an Instron 8562 $100 \mathrm{kN}$ servomechanical load frame with a crosshead speed of $1.5 \mathrm{~mm} \mathrm{~min}^{-1}$. An Instron 2620-824 extensometer captured strain across a $12.7 \mathrm{~mm}$ gage section. Both dry and saturated samples were tested to failure in ambient conditions.

\subsubsection{Acoustic emission setup and analysis}

All tests were conducted with in situ AE monitoring, using a Mistras PCI-8 Micro-II SAMOS system and two Physical Acoustics WD sensors. The sensors were connected in line with $40 \mathrm{~dB}$ external preamplifiers and featured a 50 $1000 \mathrm{kHz}$ operating range. A linear array was used to record acoustic activity throughout the tensile tests. The sensors were spaced $128 \mathrm{~mm}$ apart, each $64 \mathrm{~mm}$ from the longitudinal center of the coupon as seen in Fig. 2. A thin layer of vacuum grease was applied to ensure proper acoustic contact between the sensor and the coupon.

The MISTRAS system operated at a sampling rate of $3 \mathrm{MHz}$. A band-pass filter of 50 to $400 \mathrm{kHz}$ to eliminate noise of undesired frequencies and ensure the collected data fell in 


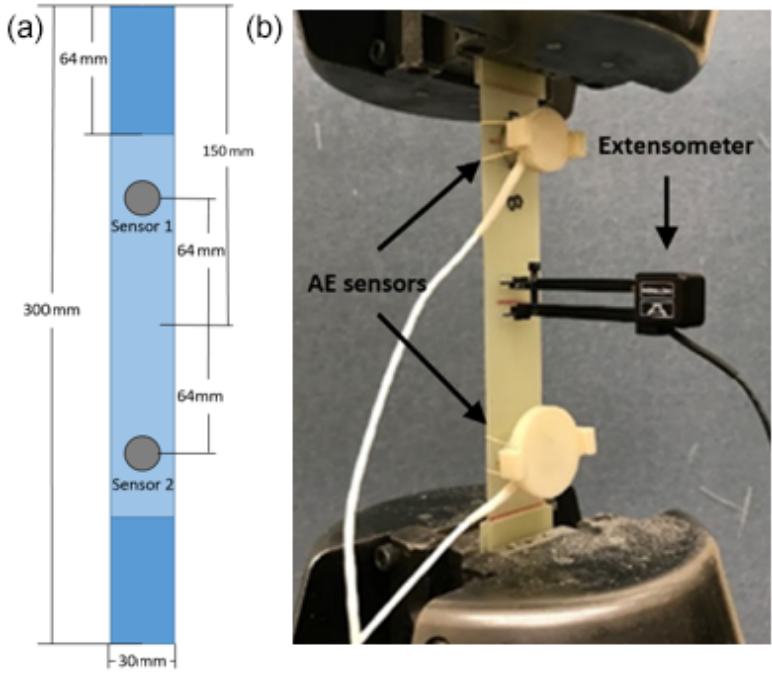

Figure 2. Coupon layout geometry and sensor layout (a). Experimental test setup (b).

the operating range of the sensors was used (2011). The timing parameters peak definition time, hit definition time, hit lockout time, and max duration were set to 50, 100, 300, and $99 \mu$ s, respectively. An AE system functionality check and a pencil lead break test were conducted prior to each test to ensure proper system setup and physical contact between the coupon and sensors.

During post processing, acoustic activity was truncated beyond the maximum load. This was for two reasons: damage after maximum load is not pertinent to damage progression in the material and extensive damage present in the sample significantly affects event propagation and attenuation. The latter may also affect $\mathrm{AE}$ events immediately preceding final failure, which is an important consideration when evaluating final damage progression.

\section{Results}

\subsection{Mechanical properties}

Average ultimate strengths of the cross-ply laminates and unidirectional laminates in each environmental condition are displayed in Fig. 3. Standard deviation error bars are added to each test group. All laminates experienced significant moisture-induced strength reductions. Cross-ply laminate strengths were reduced by $54 \%$, while the $[0]_{2}$ and $[90]_{2}$ laminates experienced 39 and $41 \%$ strength reductions, respectively.

However, it is important to note that comparing changes in strengths of unidirectional laminates to cross-ply laminates does not fully describe the lamina-level changes. Thus, ultimate unit loads were also used to compare laminates since the $90^{\circ}$ lamina add little strength in laminates with $0^{\circ}$ plies. This allows a more direct comparison of changes in load-

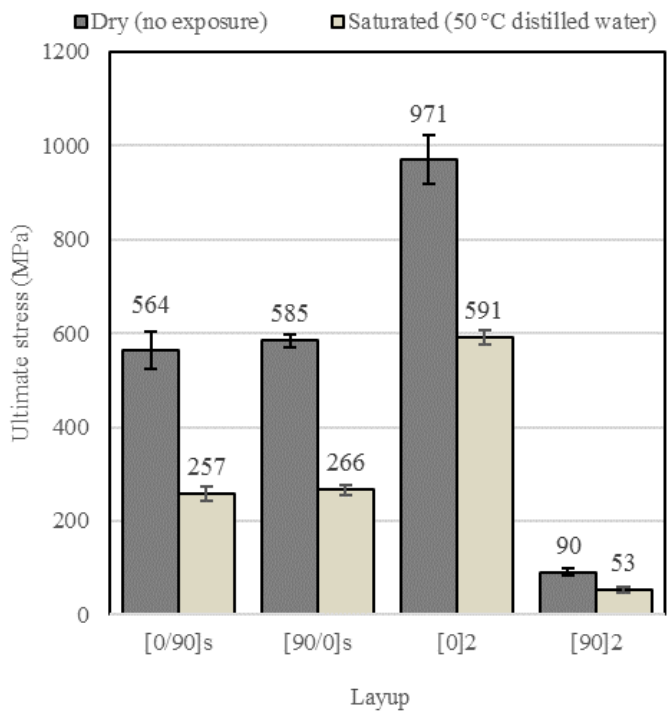

Figure 3. Average ultimate stresses of dry and saturated samples.

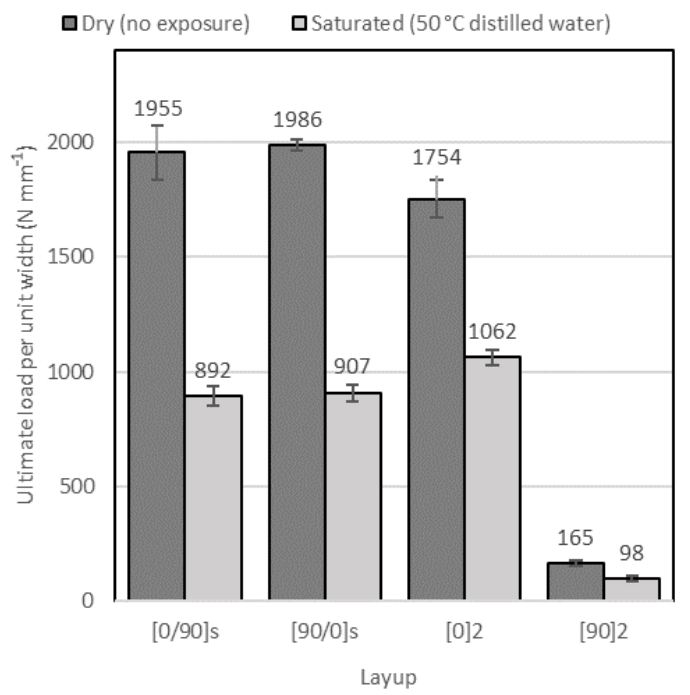

Figure 4. Ultimate loads per unit width of dry and saturated samples.

bearing $0^{\circ}$ plies. These ultimate loads are shown in Fig. 4 . In the dry condition, the cross-ply laminates' failure loads reflect the sum of the $[0]_{2}$ and $[90]_{2}$ loads. Conventionally, adding layers to a composite increases the load carrying capacity of the laminate regardless of orientation. However, in the saturated state, the opposite was true; the cross-ply laminates attained considerably lower ultimate loads than the $[0]_{2}$ laminate alone. The cross-ply laminates exhibited lower ultimate loads after saturation than the $[0]_{2}$ laminates themselves.

The typical stress-strain response for dry and saturated laminates are displayed in Fig. 5. The $[90]_{2}$ laminates show a clear change in damage progression: the knee in the $[90]_{2}$ 

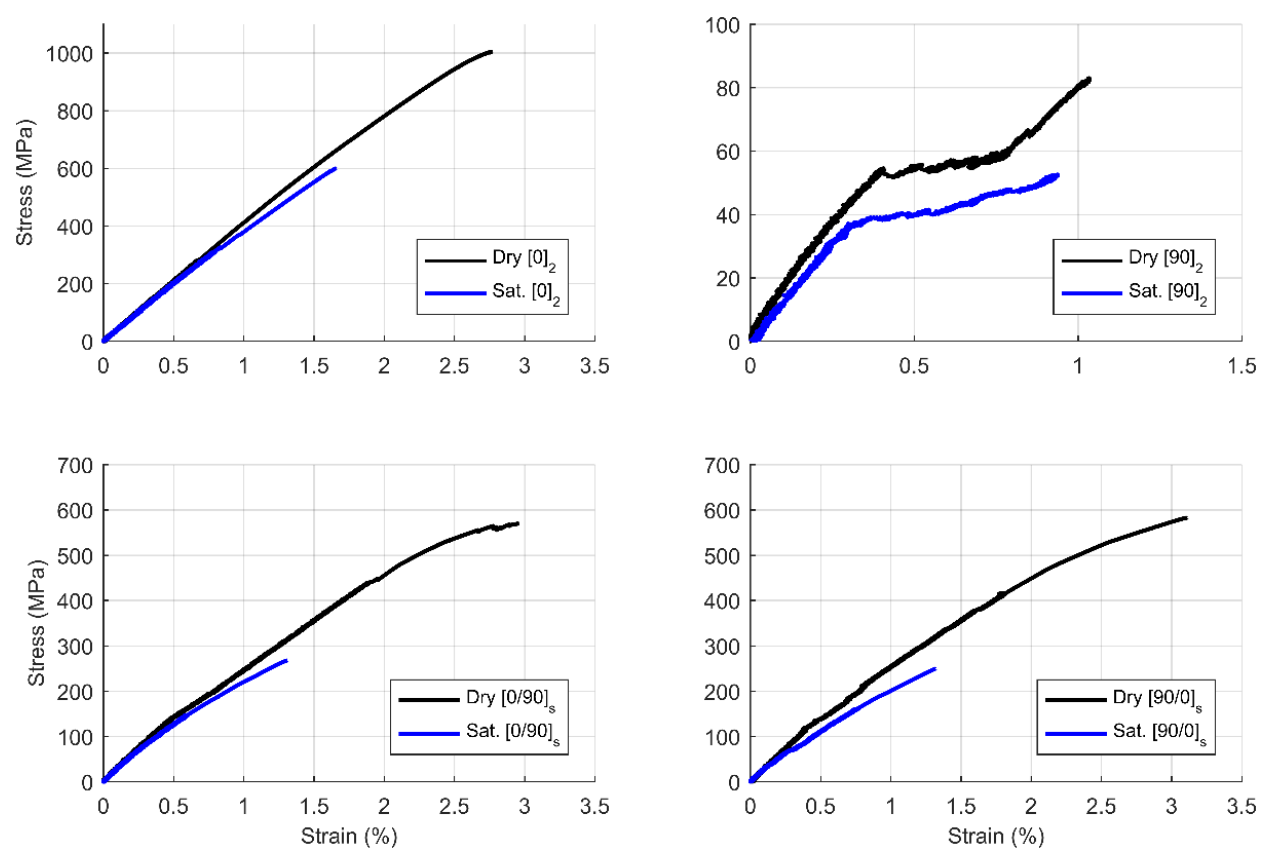

Figure 5. Stress-strain response of dry and saturated laminates.

stress-strain curve, causing a bilinear response, correlates to the onset of damage, predominantly transverse cracking, occurring at $0.43 \%$ strain in dry specimens and $0.28 \%$ strain in saturated specimens. The dry $[90]_{2}$ also feature a final increase in stiffness, causing a trilinear response, which is a result of load transfer to the small number of longitudinally oriented backing strands of the fabric; although backing strands are still present, this behavior does not occur in the saturated specimens. This stiffening effect of the dry sample could be in part due to reorientation of backing strands which typically feature some waviness or misalignment of some type; the effects of this variability could be exacerbated by local strain captured the relatively small $0.5^{\prime \prime}$ gage section of the extensometer. The stress-strain response of the saturated $[0]_{2}$ is nearly identical to that of the dry condition, however truncated at a lower ultimate stress and strain.

The stress-strain behavior of the $[0]_{2}$ and $[90]_{2}$ translates to the cross-ply laminates. The cross-ply laminates follow a response similar to the $[0]_{2}$. Both the dry and saturated samples initially follow similar stress-strain curves, but the saturated samples fail at much lower strain levels. This similarity is to be expected as the $0^{\circ}$ lamina act as the primary load bearing plies within the cross-ply laminates. Interestingly, there is slight deviation in the response between dry and saturated cross-plies at about $0.3 \%$ strain, which correlates to the lower damage initiation strain in the saturated $[90]_{2}$. The similar response of both cross-ply laminates suggests the behavior was independent of stacking sequence.

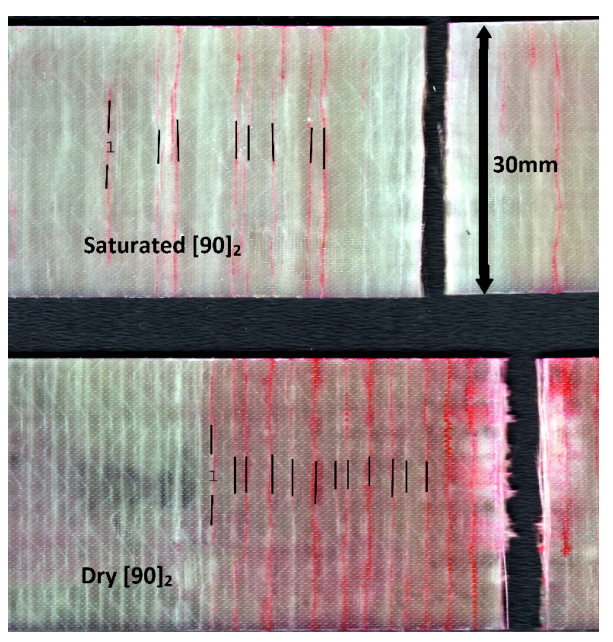

Figure 6. Transverse cracking in failed $[90]_{2}$ samples (black lines mark transverse cracks).

\subsection{Coupon failures}

Failed coupons were inspected to provide insight into changes of damage progression with moisture absorption. Images were captured with a high-resolution flat-bed scanner or digital single-lens reflex camera; Table 1 summarizes the results from the failure inspection of each laminate.

Inspection of failed $[90]_{2}$ specimens revealed a change in crack density with aging. Figure 6 shows the crack spacing of a dry sample and a saturated $[90]_{2}$ sample. Red ink was applied as a penetrant to enhance the contrast of the cracks. 
Table 1. Failure inspection results summary.

\begin{tabular}{lll}
\hline Laminate & Failure type: dry & Failure type: saturated \\
\hline$[90]_{2}$ & High crack density with consistent spacing & Low crack density with random crack spacing \\
\hline$[0]_{2}$ & High-energy tow splitting & Localized tow failures \\
\hline$[0 / 90]_{S}$ & $\begin{array}{l}\text { Brooming of outer } 0^{\circ} \text { ply and complete delam- } \\
\text { ination of } 0^{\circ}-90^{\circ} \text { interface }\end{array}$ & $\begin{array}{l}\text { Confined delamination of } 0^{\circ}-90^{\circ} \text { interface and } \\
\text { confined transverse failure of all } 0^{\circ}\end{array}$ \\
\hline$[90 / 0]_{S}$ & $\begin{array}{l}\text { Widespread delamination of } 0^{\circ}-90^{\circ} \text { interface } \\
\text { with extensive splitting of underlying } 0^{\circ} \text { tows. }\end{array}$ & $\begin{array}{l}\text { Confined transverse failure with minimal de- } \\
\text { lamination of } 0^{\circ}-90^{\circ} \text { interface }\end{array}$ \\
\hline
\end{tabular}

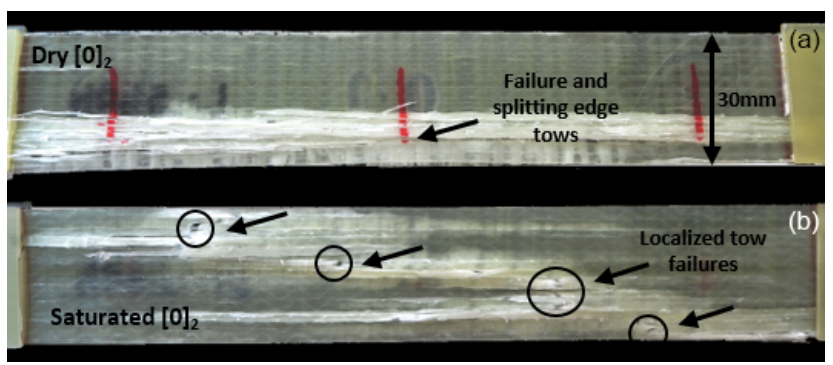

Figure 7. Failed $[0]_{2}$ coupons dry (a) saturated (b).

The crack density in the dry sample (Fig. 6 lower) is notably higher, with the cracks being uniformly spaced in correlation with each transverse tow. Conversely, the saturated $[90]_{2}$ (Fig. 6 upper) failed at a lower crack density with a more inconsistent crack spacing.

Failed $[0]_{2},[0 / 90]_{s}$, and $[90 / 0]_{s}$ coupons are displayed in Figs. 7, 8, and 9, respectively. Dry coupons containing $0^{\circ}$ plies failed at a higher rate of strain energy release than their saturated counterparts, resulting in explosive, widespread damage. This damage is illustrated by the complete tow separation in $[0]_{2}$ (Fig. 7 upper), the brooming of the $0^{\circ}$ ply in [0/90] $]_{s}$ (Fig. 8 upper), and the large delamination of the $90^{\circ}$ ply in $[90 / 0]_{s}$ (Fig. 9 upper). In the saturated $[0]_{2}$ (Fig. 7 lower), fiber tows failed in several locations, resulting in damage dispersed throughout the coupon, but exhibited very little brooming effect.

In the saturated cross-ply coupons, damage was much more localized, producing a neat transverse failure. This is shown in both the $[0 / 90]_{s}$ (Fig. 8b) and $[90 / 0]_{s}$ (Fig. 9b), where the $0^{\circ}$ tow failures occur in close proximity to each other within the gage section. This phenomenon was consistent throughout the dataset.

\subsection{Acoustic emission}

Both frequency and energy were evaluated for all the laminates tested and are discussed in the subsequent section. Table 2 summarizes the changes in AE frequency and energy results due to hygrothermal conditions for all laminates.

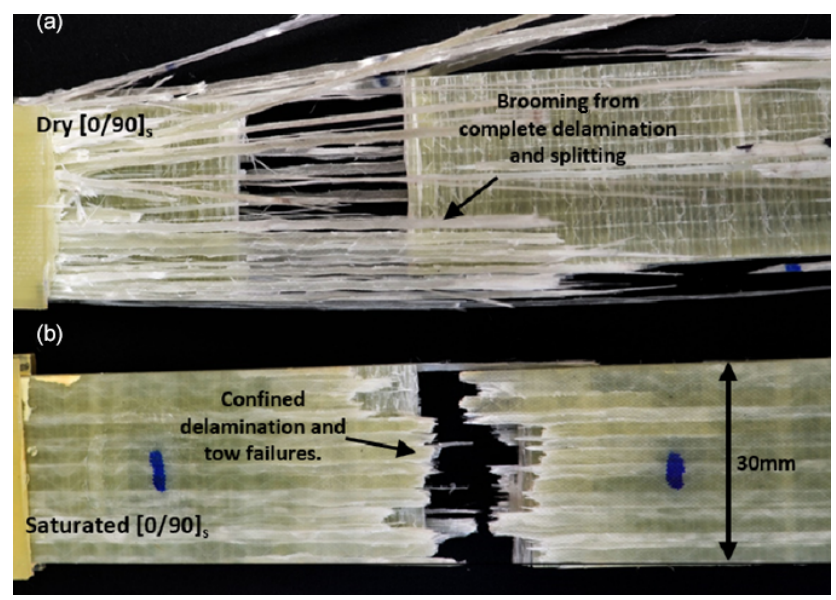

Figure 8. Failed $[0 / 90]_{S}$ coupons dry (a) saturated (b).

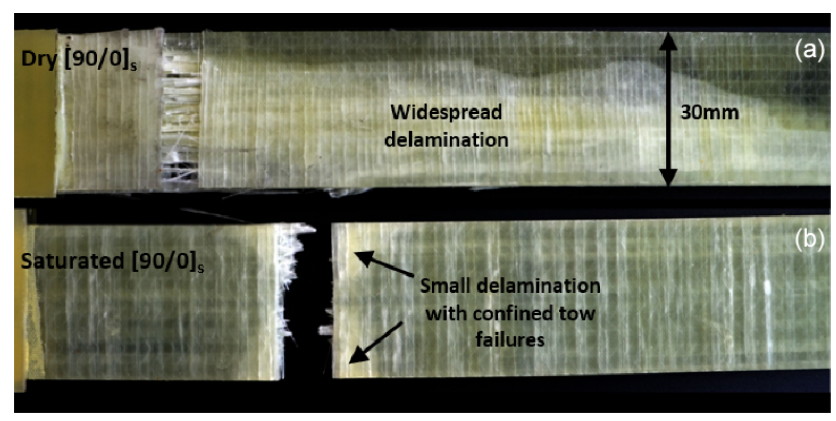

Figure 9. Failed $[90 / 0]_{S}$ coupons dry (a) saturated (b).

\subsubsection{FFT peak frequency analysis}

Previous work has shown that these FFT peak frequencies of $\mathrm{AE}$ waveforms correlate to the damage mechanisms (matrix, fiber, interphase, etc.) that caused the acoustic event (Suzuki et al., 1987; Ni et al., 2001; Bohse, 2000; deGroot et al., 1995; Ramirez-Jimenez et al., 2004). The results of these works identified discrete frequency ranges, or bins, which correlate to specific damage modes shown below in Fig. 10. Based off these works, changes in AE frequency content with conditioning can provide insight into whether the damage- 
Table 2. Summary of changes in AE response from dry conditions to saturated conditions.

\begin{tabular}{lll}
\hline Laminate & Frequency results & Energy results \\
\hline$[90]_{2}$ & $\begin{array}{l}\text { Fewer events, but frequency bands do not } \\
\text { change }(100,230, \text { and } 290 \mathrm{kHz})\end{array}$ & $\begin{array}{l}\text { Reduced AE energy throughout loading cycle. } \\
\text { Damage initiation reduced from } 0.5 \% \epsilon\end{array}$ \\
\hline$[0]_{2}$ & $\begin{array}{l}\text { Fewer events, but frequency bands do not } \\
\text { change }(100,230, \text { and } 290 \mathrm{kHz})\end{array}$ & $\begin{array}{l}\text { Reduced AE energy throughout loading cycle. } \\
\text { Damage initiation reduced from } 0.5 \text { to } 0.3 \% \epsilon \\
\text { with conditioning. }\end{array}$ \\
\hline$[0 / 90]_{S}$ & $\begin{array}{l}\text { Fewer events, but frequency bands do not } \\
\text { change }(40,100,160-250, \text { and } 290 \mathrm{kHz})\end{array}$ & $\begin{array}{l}\text { Reduced AE energy throughout loading cycle. } \\
\text { Damage initiation reduced from } 0.5 \text { to } 0.3 \% \\
\text { with conditioning. }\end{array}$ \\
\hline$[90 / 0]_{S}$ & $\begin{array}{l}\text { Fewer events, but frequency bands do not } \\
\text { change }(40,100,160-250, \text { and } 290 \mathrm{kHz})\end{array}$ & $\begin{array}{l}\text { Reduced AE energy throughout loading cycle, } \\
\text { especially between } 0.5 \text { and } 1.0 \% \\
\text { initiation reduced from } 0.5 \text { to } 0.3 \% \epsilon \text { with con- } \\
\text { ditioning. }\end{array}$ \\
\hline
\end{tabular}

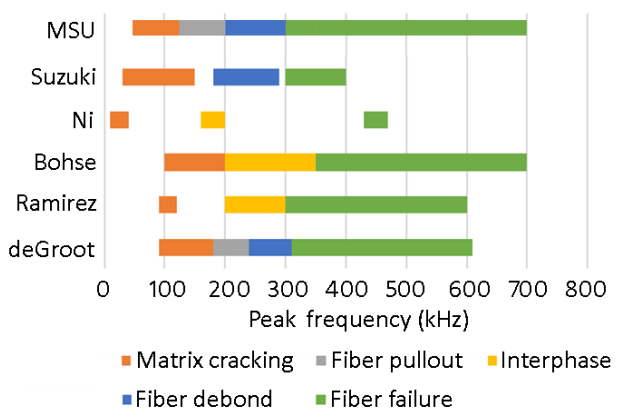

Figure 10. Frequency-damage mode correlations from various works.

present mechanisms change due to hygrothermal degradation.

The FFT peak frequency of each damage event was plotted against strain to illustrate the damage progression throughout loading. FFT peak frequency results for unidirectional and cross-ply laminates are shown in Figs. 10 and 11. Saturated samples accumulate significantly fewer events than the respective dry samples. Despite fewer events, dry and saturated samples of the same layups exhibit similar prevalent frequencies throughout the progression of damage. Distinct frequency bands are present during the loading process as can be seen in Figs. 11 and 12. In Fig. 11, the main frequency bands are located at 100,230, and $290 \mathrm{kHz}$ for the dry laminates, which do not change with conditioning. Similarly, frequency spectra of cross-ply laminates were unaffected by conditioning as shown in Fig. 12. These results would suggest that the damage mechanisms present do not change with conditioning; the micromechanical damage progression was not affected by conditioning. However, a notable difference in damage onset was evident in the AE response. The acoustic events begin to occur at lower strain levels in the saturated laminates compared to their respective dry laminates.

\subsubsection{Event energy analysis}

The event energies are plotted against strain in Figs. 13, 14 for the unidirectional and cross-ply laminates, respectively. There is a substantial change in event energies between dry and saturated samples. Acoustic events recorded from dry samples consistently reach $10^{8}$ aJ while events recorded from saturated samples rarely exceed $10^{6}$ aJ. As mentioned earlier, this phenomenon has been noticed several times throughout literature. This large reduction in energy makes comparing the event energy response from dry and saturated samples difficult; however the basic trends in AE event energy response of the dry samples can still be discerned in the saturated samples. In the dry $[0]_{2}$ (Fig. 12) there is an initial series of events centered around $0.5 \%$ strain. This peak is also present in the saturated samples; however, the event energies are much smaller. These acoustic events correspond to matrix cracking around the transverse backing tows as referenced above in the peak frequency analysis. In the dry $[0]_{2}$ tests, acoustic activity picks up again at $1 \%$ strain with progressively higher event energies throughout failure. This is also seen in the saturated $[0]_{2}$ samples but over a much smaller strain range. The progression of event energies for dry and saturated $[90]_{2}$ laminates also exhibits a similar pattern but with a decrease in event energy as well as number of events in the saturated samples.

The event energy AE results of the cross-ply laminates are shown in Fig. 14. Both laminates show an increase in number of events near failure for both conditions. Interestingly, the dry laminates feature many high-energy events with less than $1 \%$ strain that are not present in the saturated samples. The $[0 / 90]_{s}$ laminates exhibit a steady trend of increasing event energies throughout the latter half of the damage progression. This trend is not as pronounced in the $[90 / 0]_{s}$ laminates. 

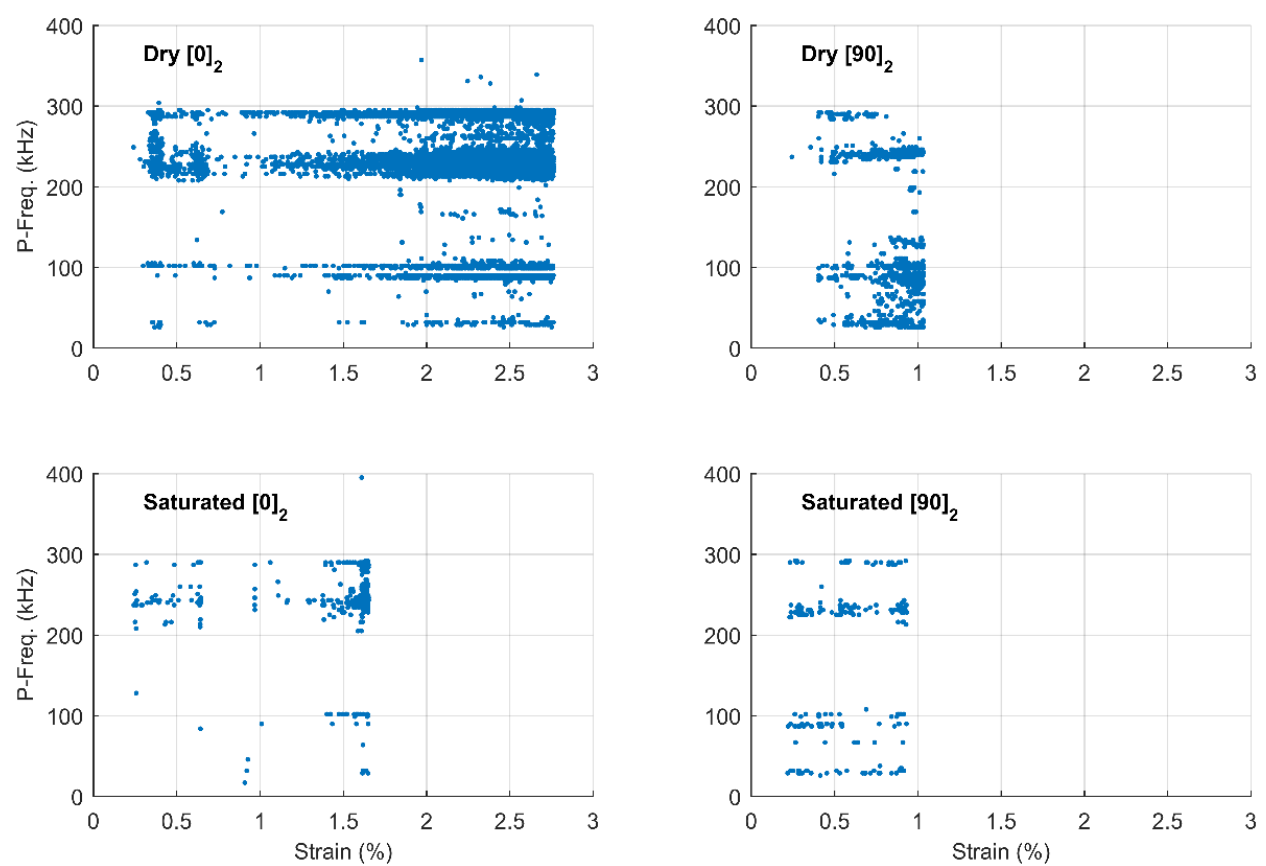

Figure 11. Typical event peak frequency versus strain for two-ply laminates.
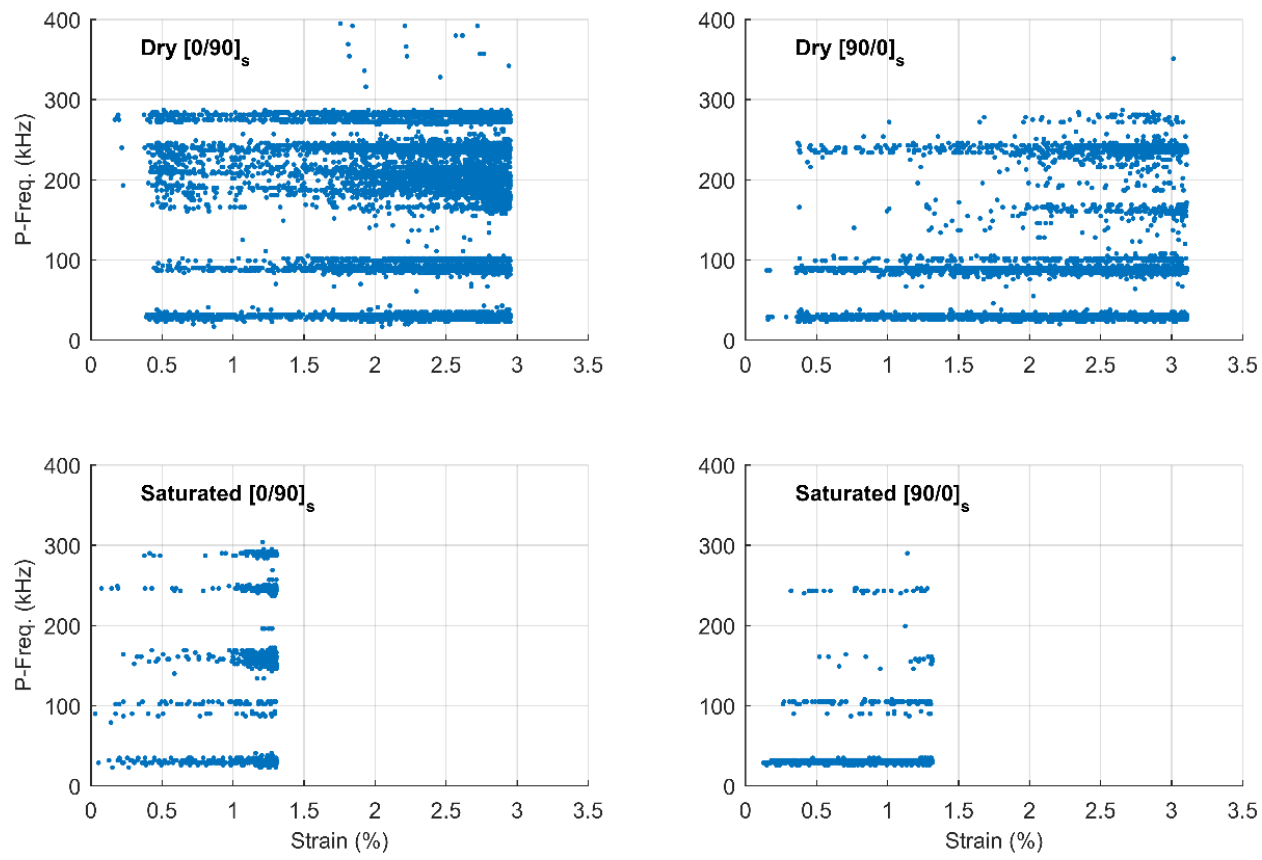

Figure 12. Typical event peak frequency versus strain for four-ply laminates.

\section{Discussion}

The substantial reduction in laminate strength (Fig. 3) shows moisture uptake to be particularly detrimental for this material system. Unidirectional laminate strengths were reduced by $40 \%$, cross-ply laminate strengths by $54 \%$. The greater strength reduction present in $[0 / 90]_{s}$ and $[90 / 0]_{s}$ laminates compared to $[0]_{2}$ laminates indicates that ply interactions significantly affect damage tolerance of the material system. Ultimate loads emphasize this effect as the saturated cross-ply (containing equivalent number of $0^{\circ}$ plies) laminates failed at a lower unit load than the unidirectional $[0]_{2}$.

The variation in damage tolerance can partially be explained by examination of damage initiation. Changes in 

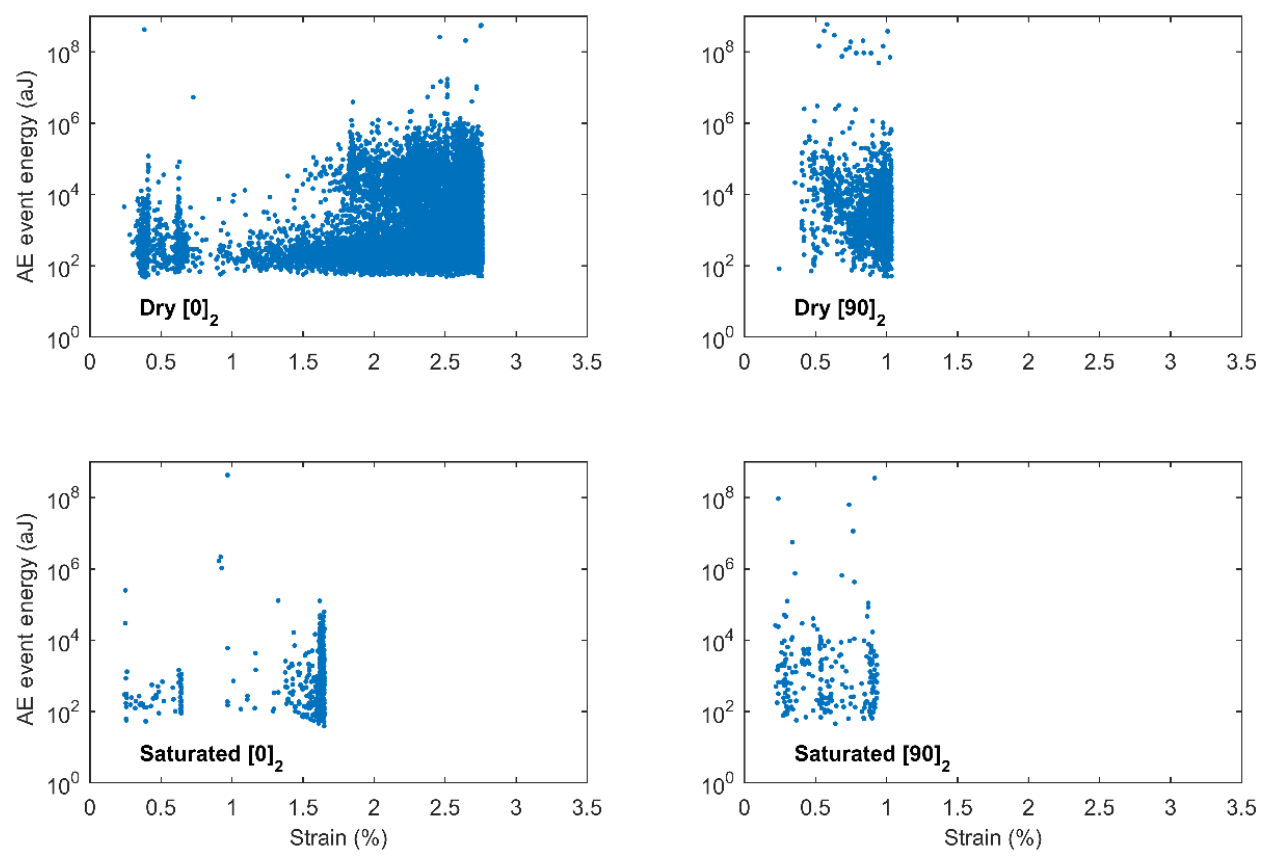

Figure 13. Typical event energy versus strain for two-ply laminates.
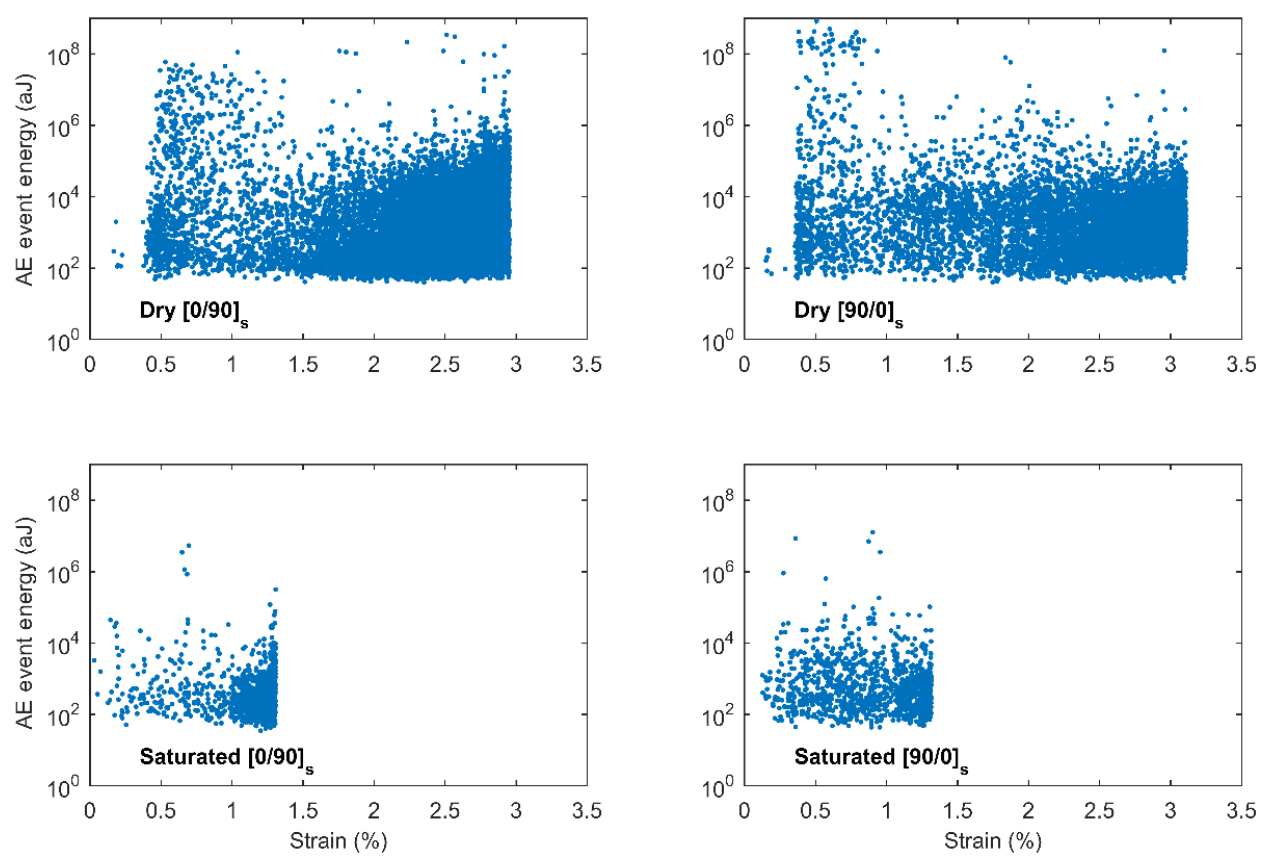

Figure 14. Typical event energy versus strain for four-ply laminates.

damage initiation were most evident in the $[90]_{2}$ layup, shown by both the knee in the stress-strain response (Fig. 5) and earlier event accumulation in the AE response (Figs. 10 and 12). Damage in transverse plies is a matrix-dominated behavior, as transverse cracks propagate through resin-rich regions in between fiber tows seen in Fig. 6. Lower strain at initiation of transverse failures in $[90]_{2}$ samples indicates degradation in the matrix due to moisture absorption. This behavior translated to cross-ply laminates, where failure in the transverse plies caused deviation in the stress-strain response at similar strain values of the $[90]_{2}$ damage initiation (Fig. 5). Again, the lowered damage initiation strain was reflected in the AE response as activity began at lower strains in saturated cross-ply laminates than their dry counterparts 
(Figs. 11 and 13). $[0]_{2}$ samples, in which transverse cracking is not a dominate mechanism, showed a negligible change in damage initiation strain with aging. It appears that the earlier initiation of damage in the transverse plies due to moisture absorption significantly affects the damage tolerance of the entire composite by introducing cracks and stress concentrations into the primary load-bearing plies.

Despite a moisture-induced change in damage initiation of the transverse plies, the subsequent damage progressions of dry and saturated laminates were remarkably similar. Stressstrain and $\mathrm{AE}$ response are the tools used to compare damage progression. Stress-strain responses of dry and saturated $[0]_{2}$ appeared nearly identical up until final failure of saturated $[0]_{2}$ (Fig. 5). Aside from the slight deviation around $0.3 \%$ strain due to premature transverse failures in saturated $90^{\circ}$ plies (Fig. 5), the stress-strain response of the dry cross-ply laminates coincided with the saturated laminates, indicating little change in the damage progression with moisture.

As mentioned previously, a decrease in AE events and energy has been associated with moisture absorption. This effect was present in this study as well; however, general trends in AE response can still be used for comparison. Dry and saturated samples of both unidirectional and cross-ply laminates experienced the same frequency spectra (Figs. 10 and 12) throughout the loading cycle, suggesting that the individual damage mechanisms present were consistent regardless of condition. Event energies (Figs. 11 and 13), despite being lower in saturated samples, followed similar patterns, pointing to a consistent damage progression in both dry and saturated samples.

The similar damage progression between dry and saturated samples suggests that the reduced ultimate strength was in fact due to reduced damage tolerance, with moisture uptake increasing sensitivity to damage, leading to premature growth. The damage growth attributed to ultimate failure can be observed by inspection of failed coupons. The transverse cracking in $[90]_{2}$ laminates (Fig. 6) showed a lower crack density in saturated samples than in dry samples, again emphasizing a change in damage tolerance, with final failure initiating from a lower damage state in the saturated samples than the dry samples. This localized damage growth at failure is witnessed in saturated $[0]_{2}$ and cross-ply (Figs. 7-9) laminates in which uniform failures were observed rather than the widespread high-energy-release failures seen in dry specimens. In dry cross-ply laminates, damage of load-bearing plies was less reactive to stress concentrations induced by failures in transverse plies. Conversely, in saturated crossply laminates, damage in transverse plies spawned premature failure in the load-bearing plies. Consistency between the results of both cross-ply layups suggests that this effect is independent of stacking sequence.

Swelling due to hygrothermal conditioning may also contribute to the changes in damage tolerance observed in this work. Specifically, moisture-induced swelling may alter the internal stress state of the material without any mechanical loads. The effects of this internal stress state may be twofold: first, the internal stress reduces the mechanical loading required to cause failure; second, the increased internal stress state may cause damage or stress concentration, which would initiate and propagate at lower strain energy levels.

This work focused on characterization of hygrothermal effects on composites subjected to a static loading; further testing would be necessary to characterize fatigue performance, which would provide useful data for MHK design. However, from the results collected in this work, it is anticipated that fatigue performance would also be significantly reduced due to hygrothermal conditioning. The premature damage initiation and reduced damage tolerance after conditioning are both attributes which could be particularly detrimental to the material lifespan in a cyclic loading regime.

\section{Conclusions}

The fiberglass-epoxy system tested in this research experienced significant strength reductions after hygrothermal aging. Unidirectional laminates experienced static strength reductions of $40 \%$ while cross-ply laminates experienced a more substantial reduction of $54 \%$. Larger strength reduction in cross-ply laminates compared to unidirectional laminates suggests the reduction in damage tolerance in a multi-angle composite is not reflected by the lamina behavior, with interacting ply behavior increasing the severity of hygrothermal effects.

Mechanical response of unidirectional and cross-ply laminates, supplemented by acoustic emission data, shows changes in the damage initiation in aged samples, as well as damage growth at final failure. When saturated, damage in transverse plies initiates at lower strains; however both the stress-strain response and AE response show consistency of subsequent damage progression compared to the unconditioned specimens. Although these data suggest that the damage progression is largely unaffected by moisture ingress into the composite, they reaffirm that moisture in fact reduces the damage tolerance. Examination of failed test specimens supports a change in damage tolerance, with saturated specimens experiencing more localized damage growth than unaged specimens. The more notable reduction in the strength of cross-ply laminates can be explained by an increased sensitivity to damage growth from transverse ply failures. This change in behavior cannot adequately be captured by laminabased tests, emphasizing the importance of laminate characterization and qualification for wind energy and MHK application.

Data availability. Data are available from the Montana State University Composite Material Technologies Research Group upon request (David A. Miller, davidmiller@montana.edu). 
Competing interests. The authors declare that they have no conflict of interest.

Acknowledgements. This research was funded by the Water Power Technologies group at Sandia National Laboratories.

Edited by: Lars Pilgaard Mikkelsen

Reviewed by: two anonymous referees

\section{References}

Assarar, M., Scida, D., El Mahi, A., Poilane, C., and Ayad, R.: Influence of water ageing on mechanical properties and damage events of two reinforced composite materials: Flax-fibres and glass-fibres, Mater. Design, 32, 788-795, https://doi.org/10.1016/j.matdes.2010.07.024, 2011.

Bohse, J.: Acoustic emission characteristics of micro-failure processes in polymer blends and composites, Compos. Sci. Technol., 60, 1213-1226, https://doi.org/10.1016/S0266-3538(00)000609, 2000.

Bourchak, M., Farrow, I., Bond, I., Rowland, C., and Menan, F.: Acoustic emission energy as a fatigue damage parameter for CFRP composites, Int. J. Fatigue, 29, 457-470, 2007.

Czigány, T., Mohd Ishak, Z. A., and Karger-Kocsis, J.: On the failure mode in dry and hygrothermally aged short fiber-reinforced injection-molded polyarylamide composites by acoustic emission, Appl. Compos. Mater., 2, 313-326, https://doi.org/10.1007/BF00568767, 1995.

deGroot, P. J., Wijnen, P. A. M., and Janssen, R. B. F.: Real-time frequency determination of acoustic emission for different fracture mechanisms in carbon epoxy composites, Compos. Sci. Technol., 55, 405-412, https://doi.org/10.1016/0266-3538(95)001212, 1995 .

Garg, A. and Ishai, O.: Characterization of Damage Initiation and Propagation in Graphite/Epoxy Laminates by Acoustic-Emission, Eng. Fract. Mech., 22, 595-608, https://doi.org/10.1016/0013-7944(85)90123-7, 1985a.

Garg, A. and Ishai, O.: Hygrothermal influence on delamination behavior of graphite/epoxy laminates, Eng. Fract. Mech., 22, 413427, https://doi.org/10.1016/0013-7944(85)90142-0, 1985b.

Grammatikos, S. A., Evernden, M., Mitchels, J., Zafari, B., Mottram, J. T., and Papanicolaou, G. C.: On the response to hygrothermal aging of pultruded FRPs used in the civil engineering sector, Mater. Design, 96, 283-295, https://doi.org/10.1016/j.matdes.2016.02.026, 2016.

Gutkin, R., Green, C. J., Vangrattanachai, S., Pinho, S. T., Robinson, P., and Curtis, P. T.: On acoustic emission for failure investigation in CFRP: Pattern recognition and peak frequency analyses, Mech. Syst. Signal Pr., 25, 1393-1407, https://doi.org/10.1016/j.ymssp.2010.11.014, 2011.

Hamstad, M.: Local characterization of fiber composites by acoustic emission, J. Acoust. Soc. Am., 73, 2230-2230, 1983.

Komai, K., Minoshima, K., and Shiroshita, S.: Hygrothermal degradation and fracture process of advanced fibrereinforced plastics, Mat. Sci. Eng. A-Struct., 143, 155-166, https://doi.org/10.1016/0921-5093(91)90735-6, 1991.
Kumar, C. S., Arumugam, V., and Santulli, C.: Characterization of indentation damage resistance of hybrid composite laminates using acoustic emission monitoring, Compos. Part B-Eng., 111, 165-178, https://doi.org/10.1016/j.compositesb.2016.12.012, 2017.

Liao, K., Schultheisz, C. R., and Hunston, D. L.: Effects of environmental aging on the properties of pultruded GFRP, Compos. Part B-Eng., 30, 485-493, https://doi.org/10.1016/S13598368(99)00013-X, 1999.

Liu, P. F., Yang, J., and Peng, X. Q.: Delamination analysis of carbon fiber composites under hygrothermal environment using acoustic emission, J. Compos. Mater., 51, 1557-1571, https://doi.org/10.1177/0021998316661043, 2017.

Miller, D., Mandell, J. F., Samborsky, D. D., HernandezSanchez, B. A., and Griffith, D. T.: Performance of composite materials subjected to salt water environments, 2012, 53rd AIAA/ASME/ASCE/AHS/ASC Structures, Structural Dynamics and Materials Conference, 23-26 April 2012, Honolulu, Hawaii, 2012.

Mourad, A.-H. I., Abdel-Magid, B. M., El-Maaddawy, T., and Grami, M. E.: Effect of Seawater and Warm Environment on Glass/Epoxy and Glass/Polyurethane Composites, Appl. Compos. Mater., 17, 557-573, https://doi.org/10.1007/s10443-0109143-1, 2010.

Ni, Q.-Q. and Iwamoto, M.: Wavelet transform of acoustic emission signals in failure of model composites, Eng. Fract. Mech., 69, 717-728, https://doi.org/10.1016/S0013-7944(01)00105-9, 2002.

Ni, Q.-Q., Kurashiki, K., and Iwamoto, M.: AE Technique for Identification of Micro Failure Modes in CFRP Composites, J. Soc. of Materials Science Japan, 50, 67-71, https://doi.org/10.2472/jsms.50.3Appendix_67, 2001.

Nogueira, P., Ramirez, C., Torres, A., Abad, M. J., Cano, J., Lopez, J., Lopez-Bueno, I., and Barral, L.: Effect of water sorption on the structure and mechanical properties of an epoxy resin system, J. Appl. Polym. Sci., 80, 71-80, https://doi.org/10.1002/10974628(20010404)80:1<71::Aid-App1077>3.0.Co;2-H, 2001.

Nunemaker, J. D.: Effects of saltwater saturation on the static strength and acoustic emission signatures of epoxy glass composites SAMPE Conference Proceedings, Long Beach, CA, 2016.

Nunemaker, J. D.: Static strength reduction and acoustic emission analysis of fiberglass-epoxy samples subjected to various levels of moisture absorption SAMPE Conference Proceedings, Seattle, WA, 2017.

Pashmforoush, F., Fotouhi, M., and Ahmadi, M.: Acoustic emission-based damage classification of glass/polyester composites using harmony search kmeans algorithm, J. Reinf. Plast. Comp., 31, 671-680, https://doi.org/10.1177/0731684412442257, 2012.

Ramirez-Jimenez, C. R., Papadakis, N., Reynolds, N., Gan, T. H., Purnell, P., and Pharaoh, M.: Identification of failure modes in glass/polypropylene composites by means of the primary frequency content of the acoustic emission event, Compos. Sci. Technol., 64, 1819-1827, https://doi.org/10.1016/j.compscitech.2004.01.008, 2004.

Samborsky, D., Mandell, J., and Miller, D.: The SNL/MSU/DOE Fatigue of Composite Materials Database: Recent Trends, 2012, 53rd AIAA/ASME/ASCE/AHS/ASC Structures, Structural Dy- 
namics and Materials Conference, 23-26 April 2012, Honolulu, Hawaii, 2012.

Siriruk, A. and Penumadu, D.: Degradation in fatigue behavior of carbon fiber-vinyl ester based composites due to sea environment, Compos. Part B-Eng., 61, 94-98, https://doi.org/10.1016/j.compositesb.2014.01.030, 2014.

Sun, P., Zhao, Y., Luo, Y. F., and Sun, L. L.: Effect of temperature and cyclic hygrothermal aging on the interlaminar shear strength of carbon fiber/bismaleimide (BMI) composite, Mater. Design, 32, 4341-4347, https://doi.org/10.1016/j.matdes.2011.04.007, 2011.

Suresh Kumar, C., Arumugam, V., and Santulli, C.: Characterization of indentation damage resistance of hybrid composite laminates using acoustic emission monitoring, Compos. Part B-Eng., 111, 165-178, https://doi.org/10.1016/j.compositesb.2016.12.012, 2017.

Surgeon, M. and Wevers, M.: Modal analysis of acoustic emission signals from CFRP laminates, Ndt\&E Int., 32, 311-322, https://doi.org/10.1016/S0963-8695(98)00077-2, 1999.

Suzuki, M., Nakanishi, H., Iwamoto, M., Jiao, G.-Q., Koike, K., Imura, M., Shigemitsu, S., and Jinen, E.: Fatigue Fracture Mechanism of Class A-SMC by Acoustic Emission Method, Journal of the Society of Materials Science, Japan, 36, 1402-1408, https://doi.org/10.2472/jsms.36.1402, 1987.
Tsai, Y., Bosze, E., Barjasteh, E., and Nutt, S.: Influence of hygrothermal environment on thermal and mechanical properties of carbon fiber/fiberglass hybrid composites, Compos. Sci. Technol., 69, 432-437, 2009.

Tsenoglou, C. J., Pavlidou, S., and Papaspyrides, C. D.: Evaluation of interfacial relaxation due to water absorption in fiberpolymer composites, Compos. Sci. Technol., 66, 2855-2864, https://doi.org/10.1016/j.compscitech.2006.02.022, 2006.

Voth, M. M.: Exploring frequency based analysis methods for damage identification in fiberglass-epoxy composite systems, SAMPE Conference Proceedings, Seattle, WA, 2017.

Voth, M. M.: Characterization of the Effects of Hygrothermal Aging on Mechanical Performance and Damage Progression of Fiberglass Epoxy Composite, Master of science: Mechanical Engineering, Mechanical Engineering, Montana State University, Bozeman, MT, 2018.

Zhou, J. M. and Lucas, J. P.: Hygrothermal effects of epoxy resin. Part II: variations of glass transition temperature, Polymer, 40, 5513-5522, https://doi.org/10.1016/S0032-3861(98)007915,1999 a.

Zhou, J. M. and Lucas, J. P.: Hygrothermal effects of epoxy resin. Part I: the nature of water in epoxy, Polymer, 40, 5505-5512, https://doi.org/10.1016/S0032-3861(98)00790-3, 1999b. 